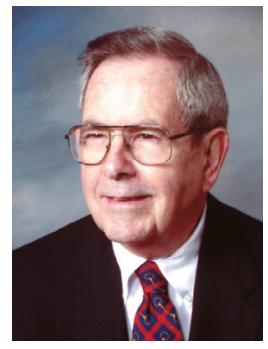

\title{
LITIGATION: AN OUNCE OF PREVENTION
}

\author{
William L. Winters, Jr., M.D. \\ Methodist DeBakey Heart \& Vascular Center, The Methodist Hospital, Houston, Texas
}

W.L. Winters Jr., M.D.

A recent avocation of mine is conducting video interviews with long-time medical staff members at The Methodist Hospital in Houston to preserve significant segments of its institutional history. The criterion for an interview is having at least a 30-year association with the hospital. You would be surprised at what I've learned about people I've worked with through all these years. Given an opportunity to talk about their lives and careers, they almost cannot be stopped; even when we ran out of videotape and were no longer on camera, they continued talking. It was not logorrhea but memories long suppressed that bubbled forth.

What really sparked my attention, during a recent interview with a cardiovascular surgeon with more than 40 years' experience in private practice, was his statement, "I've never been sued." Now that from a cardiovascular surgeon is attention-getting. I've known a few physicians who were never sued, but not one was a cardiovascular surgeon. How could that be?

I asked him to tell me his secret for keeping such a clean medicolegal slate. It wasn't because he was particularly wellinformed about risk management, although he was aware of its basic tenets. He had not been exposed to malpractice seminars as a medical student, nor did he dwell on the financial and psychological turmoil of litigation, although he heard about it often enough from his colleagues. His safeguard was this: he talked to his patients. And perhaps more essential, he talked at length and in detail to their families. He realized the importance of having a family member present when describing the surgical problem and explaining the biomedical diagnosis, prognosis, and all available treatment options. He also explained the meaning of risk.

The mortality rate for coronary artery bypass operations across the country remains at or below $1 \%$. To many in medicine, that seems very reasonable. Then he offered an analogy in the airline industry. Let's say there are 5,000 flights worldwide daily. If 1 per 100 flights (1\%) crashed per day or had an accident, 50 such accidents would occur daily, a highly unacceptable risk for air traffic. So risk is relative and dependent, in part, on other elements of an academic hospital system. Any patient undergoing a complex medical procedure may encounter any number of consultants, residents, nurses, technicians, and other medical personnel. The encounters may be brief. The more complex a patient's care, the more likely a communication error will occur. It becomes incumbent upon the patient's primary physician or surgeon to ensure seamless communication among all parties - a daunting task, indeed.
He learned the art of establishing rapport with a patient/family quickly by presenting a professional demeanor and approach that encouraged and enhanced confidence and trust. In case things didn't go as planned, he had prepared the family and the patient for possible disappointment. His forthright and humble approach, without arrogance or a "father-knows-best" attitude, enabled him to head off disappointed or disgruntled families looking for someone to blame. They were given time to ask questions and declare their expectations. I know there are physicians and surgeons who have not been sued. They will be the first to agree that meaningful communication with a patient and family is the first step toward a trusting doctor-patient relationship.

During the past 40 years, medical malpractice costs have soared, increasing an average of $11.1 \%$ annually. ${ }^{1}$ Studies have shown that the primary cause of lawsuits is not negligence but ineffective communication among patients, physicians and consultants, and families of patients. ${ }^{2}$ A humanistic, holistic, empathetic environment has been shown to reduce litigation, reduce physician burnout, and increase patient satisfaction, patient compliance, and physician satisfaction. ${ }^{3}$ The tangible influence of an empathetic physician on clinical outcomes is difficult to document, but such reports have been published. ${ }^{4,5}$ A sympathetic human presence may contribute as much to healing as well-chosen words. ${ }^{6} \mathrm{We}$ have all observed what appears to be a decline in empathy in medical students as they progress through medical school and residency programs, ${ }^{4}$ and attempts to reverse that trend are well reported. ${ }^{1,5}$ Competence is a prerequisite of professionalism, but a physician's communication skills in a holistic environment trump all other known factors in medical litigation. Furthermore, effective physician/patient communication is a lynchpin in fostering patient safety, which in turn discourages liability. For either reason, an unhurried, open conversation among stakeholders permits them to air their concerns, questions, opinions, and prejudices and, coincidentally, exposes for physicians where their patient may be uninformed or misinformed. Patients are much more likely to be satisfied if they feel free to speak their minds and know their physician is listening.

"You are in the driver's seat. The advent of managed care tends to cloud that concept, but only slightly. Notwithstanding the constraints of managed care, you still have the primary obligation to serve your patients, including being your patient's keeper, at least medically and surgically. Don't defer to a patient's decision that contravenes your best judgment for the patient's well being. 
Be sure you explain fully; then, if the patient rejects your opinion, at least you have gone the extra mile than your responsibility requires. This is a major element in the art of self defense." ${ }^{7}$ These words, written by physician attorney Don Harper Mills during the advent of managed care, resonate equally well today.

Modern medicine, with its increasingly structured requirements and time limitations, discourages and inhibits such face-to-face discussions and augments the challenges to physicians to provide the kind of personal care we would all like to receive. But one surgeon managed for 40 years to avoid the quagmire of medical legalities. So it is possible, and it benefits both patients and physicians.

Say it again Doc, in words that are clear,

To my family who are all gathered right here.

What are my choices and chances

That appropriately enhances

An outcome to be cheered by those near and dear? ${ }^{8}$

\section{References}

1. Hochberg MS, Seib CD, Berman RS, Kalet AL, Zabar SR, Pachter HL. Perspective: Malpractice in an academic medical center: a frequently overlooked aspect of professionalism education. Acad Med. 2011 Mar;86(3):365-8.

2. Liebman CB, Hyman CS. A mediation skills model to manage disclosure of errors and adverse events to patients. Health Aff (Millwood). 2004 Jul-Aug;23(4):22-32.

3. Hojat M, Louis DZ, Markham FW, Wender R, Rabinowitz C, Gonnella JS. Physicians' empathy and clinical outcomes for diabetic patients. Acad Med. 2011 Mar;86(3):359-64.

4. Rosenthal S, Howard B, Schlussel YR, Herrigel D, Smolarz BG, Gable B, et al. Humanism at heart: preserving empathy in thirdyear medical students. Acad Med. 2011 Mar;86(3):350-8.

5. Rao JK, Anderson LA, Inui TS, Frankel RM. Communication interventions make a difference in conversations between physicians and patients: a systematic review of the evidence. Med Care. 2007 Apr;45(4):340-9.

6. Nuland, Sherwin (Yale University School of Medicine, New Haven, CT). Conversation with: William L. Winters, Jr., M.D. (Methodist DeBakey Heart \& Vascular Center, Houston, TX). 2010.

7. Mills DH. The Physician's Art of Self Defense. In: Manning PR, DeBakey L, editors. Medicine: preserving the passion of the 21st century. New York: Springer-Verlag; 2004. p. 360.

8. The movie, "Casablanca." With apologies. 